Int. J. Electrochem. Sci., 15 (2020) 2766 - 2775

International Journal of

ELECTROCHEMICAL

SCIENCE

www.electrochemsci.org

\title{
An Electrochemical Approach for the Determination of the Fruit Juice Freshness Using Carbon Paste Electrode Modified with ZnO Nanorods
}

\author{
Huali Tang ${ }^{*}$, Tao Gao, Zhenyu Luo \\ College of biology and food engineering, Chongqing Three Gorges University, Chongqing, 404120, \\ PR China \\ *E-mail: Hualitang220@126.com
}

doi: $10.20964 / 2020.03 .37$

Received: 29 September 2019 / Accepted: 12 November 2019 / Published: 10 February 2020

\begin{abstract}
The presence of citric acid in food products is directly related to their color and taste, leading to the freshness of the products. Here, detection of citric acid in fruit juice were investigated using $\mathrm{ZnO}$ nanorods based carbon paste electrode (Z-CPE) through the electrochemical methods. A facile aqueous solution technique was used to synthesize $\mathrm{ZnO}$ nanorods and $\mathrm{Z}$-CPE was prepared by dropping the dispersed $\mathrm{ZnO}$ nanorods in methanol on the surface of CPE. X-ray diffraction, transmission electron microscopy and field emission scanning electron microscopy analyses of prepared $\mathrm{ZnO}$ nanorods showed the $\mathrm{ZnO}$ nanorods were synthesized in high density of hexagonal phase. Cyclic voltammetry, differential pulse voltammetry, and electrochemical impedance spectroscopy techniques were conducted for electrochemical study of Z-CPE. Electrochemical analyses showed charge transfer behavior was facilitated due to the presence of high aspect ratio and high effective surface area of $\mathrm{ZnO}$ nanorods in the electrode surface. Study on the concentration effect of citric acid on Z-CPE indicated a linear relationship between peak current and citric acid concentration $(0.5 \mathrm{mM}$ to $6 \mathrm{mM}$ as calibration range). The detection limit and sensitivity of citric acid sensor were estimated $0.998 \mu \mathrm{A} / \mu \mathrm{M}$ and $3 \mathrm{nM}$, respectively. The results show that $\mathrm{ZnO}$ nanostructures can be of great help to enhance electrochemical sensors for detection of citric acid as an important element in juices, especially citrus fruits.
\end{abstract}

Keywords: $\mathrm{ZnO}$ nanorods; Carbon paste electrode; Citric acid; Electrochemical technique; Cyclic voltammetry; Electrochemical impedance spectroscopy

\section{$\underline{\text { FULL TEXT }}$}

(C) 2020 The Authors. Published by ESG (www.electrochemsci.org). This article is an open access article distributed under the terms and conditions of the Creative Commons Attribution license (http://creativecommons.org/licenses/by/4.0/). 